\title{
Beyond Keeping It Real: OutKast, the Funk Connection, and Afrofuturism
}

\section{Howard Rambsy II}

The notion of "keeping it real" has long been a hallmark of hip-hop culture. Rappers in particular and hip-hop heads in general gain their worth in part based on their abilities to channel and exhibit recognizable aspects of the hood or distinct black communities. Keeping it real presumably counters falsehoods and allows people to forgo seemingly passive practices, such as lying, masking, signifying, and other cultural behaviors linked to African Americans, concealing their true selves and feelings in the face of powerful authoritative forces. ${ }^{1}$ For some, keeping it real means rejecting ostensible white or Eurocentric rules of decorum in favor of taking problack positions. And still for others, keeping it real simply means adhering to supposedly accepted forms of behavior based on the standards of "the black community," a phrase that is often quite slippery. The tendency to keep it real or "keep it 100," as Chicagoans associated with hip-hop say, does have practical and political significance, and there is some positive value with indicating that people should show some love to their home communities, especially communities that have been historically neglected. Nonetheless, given the important though underdiscussed and sometimes suppressed boundary-pushing artistic productions and imaginative work of black men, we might benefit by thinking more seriously about moving beyond keeping it real.

"Black creative life has too often been determined by this impulse to 'keep it real," sociologist Alondra Nelson has explained. "In order to be taken seri- 
ously, we have fostered and encouraged a long tradition of social realism in our cultural production. And we feared that to stop keeping things real was to lose the ability to recognize and protest the very real inequities in the social world." The problem, Nelson points out, is that "we created a cultural environment often hostile to speculation, experimentation, and abstraction." ${ }^{2}$ For Nelson and many others associated with Afrofuturism - a framework for thinking about the intersections of race and technology - black diasporic cultural traditions contain speculative narratives, innovation, and engagements with science, machines, and technological devices that deserve more of our attention if we are to fully appreciate the nature of those traditions. Music, for centuries now, has been one of the most consistently innovative sites in black creative life; thus, not surprisingly, thinkers interested in Afrofuturism and African American culture in general have viewed black music as a vital source of knowledge. Although hip-hop has a prominent "keeping it real" streak, the field has also been regularly populated by presumably accomplished leaders in the field interested in pushing and reshaping boundaries.

At a key moment in the history of rap music, the group OutKast emerged and offered one possibility for thinking beyond the genre's more dominant realist conventions. The moment was key, in retrospect, because the geographic terrain of hip-hop was expanding into the South. The duo of Big Boi and André 3000 (previously known as Dré) and the production company Organized Noize made it possible for OutKast to present conceptual ideas that departed from typical hip-hop narratives. A close look at OutKast's work provides an opportunity to see how they advanced and expanded conventional notions of rap by infusing their compositions with past traditions of black music, namely, funk. In addition, the funkadelic, futuristic, and seemingly unfamiliar, weird, or eccentric persona projected by André 3000 creates the chance to transcend the more pronounced characterizations of gangstas and pimps so regularly assumed by black men rap artists. To say that Andre 3000 was perceived as "weird" means that audiences could have questioned whether or to what extent he was keeping it real. Despite hip-hop's adherence to real street culture, André 3000's status as an eccentric yet popular black artist reminds us that innovation, speculative fiction, and sci-fi personages are just as integral to the art form.

For years, rap music and black men have been recurring notable subjects in popular and scholarly discourses. A wide range of scholars and journalists have contributed to the expansive body of articles, media coverage, books, academic conferences, and college courses focusing on hip-hop and rap artists. At the same time, news reporters and sociological studies have largely concentrated on struggling black men, including those who are low income in inner cities and those who are classified as "criminals." Actually, images of thugs, gangstas, hustlers, and ex-cons are prevalent in discourses on hip-hop and black men. Less prevalent are narratives about the creative and intellectual development of musical artists and the processes by which they experiment with, develop, and solidify distinct styles of artistic production. A look at the funk connections of 
OutKast's early career and the ways that one of its members, André 3000 , benefited from networks of artistic support provides an alternative to keeping it real. ${ }^{3}$

\section{The Funk and Speculative Qualities of a Southern Rap Group}

When OutKast's first album, Southernplayalisticadillacmuzik (1994), was released and began to gain wide appeal, hip-hop culture had few nationally and internationally known southern rap groups. By and large, the most prominent rappers were from the East and West Coasts, and those regions generated the most extensive coverage among media outlets and scholars concerning subjects related to hip-hop. There were artists and groups that preceded OutKast, such as the Geto Boys, 2 Live Crew, Kriss Kross, and UGK, and during the mid- to late1990s, So So Def Recordings, Cash Money Records, and No Limit Records also emerged. OutKast - a name signifying the duo's outsider status in relation to the East/West paradigm - was part of the geographic shifts and expansion in hip-hop where southern rap artists would become increasingly important to narratives about the development of hip-hop. Ironically, the rise of southern rap groups during the mid- to late-1990s coincides with the decline of the "Golden Age" of hip-hop, a time period that observers designate as taking place between the mid-1980s and the mid-1990s. ${ }^{4}$ If hip-hop's Golden Age was, in fact, in decline, OutKast and their fellow regional artists did not receive the memo, or their identity as an Atlanta-based group meant that they were in a key position to enter the crowded field of rap and produce something new.

In African American jazz circles, notes Lewis Porter in his biography of John Coltrane, the development of a signature sound "is the most valued goal" among musicians. ${ }^{5}$ They absorb large bodies of work, switch and alter instruments, emulate sonic and physical techniques of other musicians, master multiple and subtle qualities of sound, and blend various influences, all in efforts to develop their musical vocabularies and produce distinct compositions. ${ }^{6}$ In some respects, OutKast and many other rap artists also placed a premium on the goal of achieving a signature sound. Big Boi and André 3000's southern style of rapping and the funk-driven nature of music provided by Organized Noize made Southernplayalisticadillacmuzik an especially original contribution to hip-hop discourse. The tales of street culture that the duo provided were, generally speaking, somewhat conventional. However, quick-rhyming rappers with southern accents and terminology and music with guitar licks, strong bass lines, and overall grooves that resembled and re-created qualities of funk did indicate the rise of a new, distinguishing sound. Southernplayalisticadillacmuzik "reveals a deeper understanding of the funk," noted Rob Marriott in a review of the album for The Source. "The OutKast sound doesn't just ride atop the funk. It aspires to it."

OutKast's funk connection, that is, their links to the rhythm-driven, electric bass and guitar music that was a distinctive feature of their sound, could 
be attributed in part to Patrick "Sleepy" Brown — one of the three founders of Organized Noize. "Sleepy" Brown's father, Jimmy Brown, has a long career as a vocalist, saxophonist, and flutist with the Atlanta-based funk group Brick. The band's biggest hit, "Dazz," signaling a blend of disco and jazz, is also a funk tune, having gained wide appeal in rap discourse when Dana Dane sampled aspects of Brick's song in his popular "Cinderfella Dana Dane" from 1988. "Sleepy" Brown's contributions to OutKast's music constitute a key intergenerational link to funk. Aspects of his productions can be understood as extensions and alterations of the work produced by bands like his father's group. Thanks to "Sleepy" Brown, OutKast's music exhibited an even sturdier kinship to an older generation of music beyond rap. One of Brown's first major funk-related contributions to the rap group was his composition of the chorus for "Player's Ball," Big Boi and André 3000's first hit single. Brown employs a falsetto register as he sings the chorus for the song, unmistakably channeling the signature sound of Curtis Mayfield - an important contributor to funk.

Among other attributes, the presence of funk in Outkast's music also means that the group's work contains skilled live instrumentation the likes of which characterized music and performances by James Brown's bands, Parliament-Funkadelic, the Isley Brothers, Sly and the Family Stone, and various others. The spirits of funk, with the prevalent grooves led by the electric organ, synthesizer, electric bass, electric guitar, and drums, are quite pronounced on OutKast's songs, such as "Claimin True," "Crumblin' Erb," "Player's Ball," "Player's Ball (Reprise)," and "Hootie Hoo." At the close of "Player's Ball," by the way, André gives a shout-out to Parliament-Funkadelic's nickname when he raps. "A five fo' a three two here comes the one / A new year has begun, P-Funk spark another one." Along with "Sleepy" Brown and Organized Noize, the contributions by Craig Love on guitar, Preston Crump on bass, and LaMarquis (Marq) Jefferson on bass serve as additional connective funk threads that appear on much of OutKast's music. The playing by Love, Crump, and Jefferson, and more broadly the regular, strong presence of electric guitars and basses as well as soulful background vocals sung by small ensembles on OutKast's tracks assisted in distinguishing their sound from prominent East and West Coast rap music.

Alondra Nelson has explained that some creations by artists "reflect the long and impressive history African diasporic culture, but also push the envelope of these traditions" and thus amount to "past-future visions." Accordingly, "past-future vision" emerged in OutKast's work as they seemed to draw on and extend features of funk. The group embedded elements of the music in their songs and created a signature sound in rap - a sound that was linked to rich artistic traditions produced and performed by countless funk bands and a sound that differed from the conventions of keeping it real, at least in commercial rap music of the day. As previously noted, the development of a signature sound is a valued goal in realms of black musical production. The distinct sound that OutKast produced made it possible for their work to gain recognition in a field 
that is incredibly overcrowded and difficult for artists to receive notice. Interestingly, in the process of further differentiating the look and sound of their creations from other music, the rap group would, by their second album, stylize themselves as sci-fi and futuristic, similar to approaches popularized in previous decades by funkmaster George Clinton.

OutKast's second album, ATLiens (1996), highlighted the idea of the group and, more broadly, Atlantans and others connected to the duo's music as kinds of alien beings. Prior to their emergence in 1994, Big Boi and André 3000 planned to title their rap group "2 Shades Deep" and then "The Misfits" before arriving at the moniker "OutKast," a name that consequently made it easier for them to take the next steps of envisioning themselves as extraterrestrial. The notions of flight and outsideness have long histories in black artistic culture, and certainly the contemplations about aliens that OutKast displayed with ATLiens coincided with more recent concepts associated with space travel expressed in the music and stage performances of George Clinton and his Mothership on the one hand and jazz musician Sun Ra on the other hand, who, in addition to producing the signature tune "Space Is the Place," starred in a movie of the same name. Given the prevalence of narratives about street culture in hip-hop, OutKast's alienthemed album seemed especially unusual in comparison to what many listeners were accustomed to hearing in rap.

With song titles such as "ATLiens," "Babylon," "Elevators," "E.T. (Extraterrestrial)," and "13th Floor," the group was concerned with taking their music, rap in general, and perhaps black people to less charted realms. To prompt an otherworldly interpretation of the group's second album, the liner notes booklet for ATLiens resembles a small comic book with illustrations of Big Boi and André battling "the Dark Horde, upholders of evil censorship, enemy of all that's righteous." The cover of the CD booklet shows cartoon-drawn images of what are presumably the two rappers surrounded by sinister villains. In the image, Big Boi and André 3000 stand ready to defend themselves against the evil forces. The upper left-hand corner of the image includes a supposed publication date "1 Aug." and price "\$2.99 / \$1.50 Can.," further emulating the look of a comic book. Before many consumers heard any of the tracks on ATLiens, they were oriented to the group as heroic, alien-like characters in the spirit of figures from the universes of Marvel and DC Comics, not simply the real and mortal beings inhabiting the world of rap music.

Similar to Clinton and Sun Ra, both of whom assumed outer-space personas, OutKast was aligning itself with African American sci-fi and celestial musical discourses. In the realms of jazz, Sun Ra's expansive discographywith albums such as Interstellar Low Ways/Rocket Number Nine (1960), Other Planes of There (1966), We Travel the Space Ways (1967), and Space Is the Place (1972) as well as his Myth Science Arkestra's spacelike wardrobe - signaled an active engagement with intergalactic ideas. According to Sun Ra, he decided to have his band members wear far-out costumes to make it evident to African Americans that "there are other things outside their closed environ- 


\section{Howard Rambsy II}

ment." In realms of funk, Clinton's Parliament-Funkadelic are particularly well known for their explorations of worlds beyond Earth. Most notably, the group's signature concert moment was the arrival of the Holy Mothership - the space vehicle of Dr. Funkenstein, one of Clinton's alter egos. The elaborate and dynamic stagecraft that allowed for an apparent spaceship to land onstage, the complementary P-Funk characters and ideas, and the "weird" and outrageous costumes worn by Clinton, Bootsy Collins, and other band members all contributed to a broad body of black sci-fi, space travel, and futuristic aesthetics. Rap's early histories, of course, had links to these types of aesthetics with break dancers embodying the roles of robots, helicopters, and moonwalkers; human beat-boxers projecting electronic sounds; and turntablists producing innovative musical productions. Ultimately, OutKast's ATLiens synthesizes techno and sci-fi qualities from rap and funk, contributing overall to the group's distinct sound and look.

On the level of lyrics, ATLiens contains many raps about street life-a typical approach in hip-hop. However, the positioning of the work within sci-fi or outer-space discourse with the liner note booklet resembling a comic book and the alien-related album and song titles empowered OutKast to deviate from the usual narratives about the hood and thug life. Kevin Powell opened his review of ATLiens for Rolling Stone by noting that the title of the group's album "suggests that the Atlanta based rap duo is spaced out on a P-Funk-style otherworldly trip." Powell went on to explain that what distinguished OutKast's album from "the materialistic hedonism of much East Coast rap, and the gunplay and pimpism of its West Coast counterpart" was the group's "unique ability to describe ghetto life while offering up life-affirming possibilities, something all too rare in today's hip-hop nation."10 The juxtaposition of "ghetto life" with far-off places on OutKast's album reveals a rap group imagining alternative possibilities for listeners, something beyond the notion of keeping it real.

That OutKast is from the South, a region long associated with backwardness and the unhip, makes it even more important that they produced an original highly praised sound and offered a futuristic vision for rap. By earning acclaim

as a leading force in the field, the southern rap group was simultaneously redrawing the geographic lines of hip-hop, paving the way for subsequent artists from the region. The presence of funk-related sounds and Sun Ra- and George Clinton-like otherworldly explorations on Big Boi and André 3000's foundational albums contributed to the group's ability to distinguish themselves among their peers, which is quite important given the highly competitive and densely populated nature of rap. Thus, OutKast's achievements represented a solution to an underdiscussed problem concerning keeping it real in rap: the production of popular and, at the same time, surreal music. 


\section{André 3000, Black Men, and Creativity}

One of the most distinguishing features of OutKast, which is to say, one of the qualities that makes the group really stand out among others, is André 3000. Over the course of his career, he became known for his conscious or intellectually astute and politically aware and surrealist lyrics, his varied voice inflections while rapping, and his outrageous fashion choices. Unlike many rappers, including his partner Big Boi, André 3000 did not always display the familiar elements of street culture. Instead, he seemed to reside on other planes of there, to invoke the title of a Sun Ra album. Andre 3000's willingness to differentiate himself from the conventional personas of pimps, thugs, or drug dealers that are so prominent among black male rappers could be read as an act of creativity, an artistic effort to create an identity that is not prepackaged. Consequently, in scholarly conversations about black men, the significance of such efforts is often overlooked.

The most expansive body of scholarly work on black men, which tends to emerge in the field of sociology, usually concentrates on their troubled conditions. Works such as William Julius Wilson's When Work Disappears: The World of the New Urban Poor (1996), Ronald Mincy's edited collection Black Males Left Behind (2006), and Elijah Anderson's edited collection Against the Wall: Poor, Young, Black, and Male (2008), to name a few, address the dire socioeconomic circumstances concerning young men. Studies like those are quite useful for understanding the challenges that black men are up against. For decades, scholars of African American literature have produced work on the artistic productions of leading black men writers, but by and large, the scholarship concentrates on older canonical literary artists. The scholarship on hip-hop is expansive and ever growing it seems; nonetheless, the focus, not surprisingly, is primarily on the music, celebrities, controversies, and popular trends within the field. High-profile commentators, from Fox news television host Bill O'Reilly to comedian Bill Cosby to President Barack Obama, who offer their thoughts on rap culture usually mention the characteristic problematic results and representations of hip-hop. Scholarship - in sociology, literature, African American studies, and rap - and commentators rarely deal with the creative and intellectual lives of young black men.

Without more discussions of the many possible impulses that inspire men and young boys to want to spit rhymes and achieve distinct styles of representation and without more conversations about the environmental factors that assist in cultivating their creativity and devotion to the music, we will fail to fully understand the artistic thought of large numbers of black men. An artist like André 3000 is fascinating as a subject because of how his presence challenges preexisting normative views of rappers, and at the same time, he provides a compelling model for what it means to be a boundary-pushing or, better, a progressive boundary-pushing creative black man in the realm of hip-hop. His status as the stranger side of the OutKast duo was in fact a manifestation of his 


\section{Howard Rambsy II}

artistic ability to move beyond the mask of keeping it real in rap. Scholar Tricia Rose has explained that rhetoric associated with keeping it real acts as "a cover for perpetuating gross stereotypes about black people - stereotypes that have deep roots in American culture." ${ }^{\prime 11}$ A successful artist like André 3000 who does not keep it real in conventional ways offers small but salient alternatives to such narrow stereotypes. His adaptations of varied voice inflections and paces while rapping and his engagement of sociopolitics in Georgia (e.g., in "D.E.E.P.," he calls on the Atlanta mayor to resist raising the Confederate flag) reveal an artist who is willing to forgo usual thug life narratives in order to chart original and astute directions in rap discourse.

Years ago, participants involved in discussions on the "afrofuturist list" regularly discussed music and the various techniques utilized by artists to achieve particular sounds. ${ }^{12}$ One way, drawing on Afrofuturist discourse, of appreciating André 3000's creativity and perhaps the creativity of various black men seeking to develop a distinct sound, is to pay attention to the techniques that they deploy in order to pursue and produce various results. In the context of Afrofuturism, André 3000's tendency to augment his voice in different songs, his fondness for exuberant wordplay (e.g., he opens "Chonyfire" asserting "Yooskee, Wooahskee / Peeskee Weeskee"), and his frequent references to extraterrestrials are a few of his defining technical approaches that shape the distinctiveness of his artistry. Recognition of the many techniques that André 3000 utilizes as he raps requires a broad understanding of African American expressive culture and traditions. Further, an awareness of André 3000's high level of technical skills also means appreciating the fact that some black men artists absorb rather complex black musical, poetic, and performance histories at a fairly young age. André 3000 's artistic compositions are the results of much collaboration and indicate that his talents and works are linked to multiple communities of creative black men. He is an extraordinary artist no doubt, but as Malcolm Gladwell has explained, such "outliers" or highly accomplished people "are invariably the beneficiaries of hidden advantages and extraordinary opportunities and cultural legacies." 13

André 3000's musical cultural legacies stretch back through the Golden Age of hip-hop to R\&B to funk to jazz and the blues. His verbal skills reveal that he is a beneficiary of rich linguistic and expressive traditions that include southern African American Vernacular English, black male toasting, comedic and storytelling practices. His black political consciousness, which contains traces of Malcolm X-like characteristics, suggests that he likely participated in those many hidden networks of street-scholar black men-intellectually adept brothers whose imprints are evident throughout rap discourse. ${ }^{14}$ The presence of Goodie Mob on Southernplayalisticadillacmuzik signals that Big Boi and André 3000 were involved in a larger community of artists and "conscious" thinkers early on in their careers. Although André 3000 is arguably the most widely known figure associated with the collective of southern musicians known as the Dungeon Family, his artistic sensibilities and outlook were forged in the 
midst of that community. ${ }^{15}$ André 3000's participation in these communities of artists was an extension of the creative, informal learning and practice environments long established by members of funk bands and jazz groups. Accordingly, James Brown, George Clinton, Sun Ra, Miles Davis, and John Coltrane may have been the most famous figures to emerge from their respective groups, but their music and distinct sounds were always shaped by artistic communities and those bands of artists from which they sprang.

The broader fields of rap music and the local community of Atlanta artists, especially the Dungeon Family, provided André 3000 with a context to develop his craft and identity as a rapper and entertainer. His rap partner Big Boi was perhaps his most vital collaborator and point of departure. By the time of their second album, André 3000 appeared to be far more artistically experimental than he was on Southernplayalisticadillacmuzik. The presence of Big Boi, who continued to offer more conventional narratives associated with street culture, displayed familiar aspects of rap music necessary for appealing to a core hiphop audience. At the same time, Big Boi's commitment to keeping it real enhanced the divergent paths taken by André 3000. On their song "ATLiens," for instance, Big Boi offers straightforward toasts and battle lyrics, whereas André 3000 ponders issues about the future of African Americans by posing questions to a potential woman partner about whether "the child we raise gon' have that nigga syndrome" or "will it know to beat the odds regardless of the skin-tone?" Notably, in the last verse of the song, he announces that he does not intake "drugs or alcohol so I can get the signal clear," and he no longer needs a gun because "I got a stronger weapon," which could be his lyrical skills, mental capabilities, and spiritual beliefs. ${ }^{16}$

The noticeable contrasting differences between the street hustler Big Boi and the increasingly philosophical and conscious André 3000 created a compelling sense of cognitive dissonance within the duo. André 3000's move toward breaking artistic boundaries on ATLiens is admirable and refreshing, yet the positive reception of his breakthroughs would have been less possible without Big Boi's recognizable keeping-it-real ethos and without the substantial success of the group's first album, Southernplayalisticadillacmuzik, which was less cutting edge, at least artistically, than ATLiens. The early commercial success of OutKast's first album gave the rap group and especially André 3000 the security and freedom necessary to take more daring artistic risks on subsequent albums. In retrospect, it is remarkable just how extensive the support systems were and had to be in order to sustain a rap artist's interest in taking more innovative approaches.

In André 3000's case, he was, as noted, a member of an up-and-coming talented artistic community, the Dungeon Family, and costar of a new musical duo that had swiftly gained fame and recognition in a then untapped southern hiphop market and in a quickly expanding global market for U.S. rap. The group's track record and potential for earning high profits meant that they would have formidable financial and marketing backing from their parent companies-La- 


\section{Howard Rambsy II}

Face Records and Arista Records. These considerable factors, along with adoration from fans and the music industry, fueled the supportive and well-resourced creative environment that would assist André 3000 as he sought to diversify his methods of artistic production. The extraordinary levels of support that André 3000 received reveal that deviation from keeping it real or, better yet, the development of a body of boundary-pushing creative musical works depends on more than simply individual artists' desires to produce original compositions. Sure, that matters. However, in addition to possessing adequate levels of talent and high creative aspirations, commercially successful rap artists who move beyond the realms of keeping it real are ultimately the beneficiaries of remarkable networks of support.

No wonder André 3000 was and remains such a rare figure in the history of rap. His artistic advancement constituted an uncommon, multifaceted undertaking that was facilitated by assistance and regular collaborations with a broad range of participants, including several astonishingly talented musicians, such as Sleepy Brown, Big Boi, Cee-Lo Green, and executive producers "L.A." Reid and Kenny "Babyface" Edmonds. Large numbers of young black men might have the creative ambitions of an André 3000, but few are likely to have access to such tremendous financial, market, and artistic support at critical stages of their development. Nearly fifty years before the release of Big Boi and André 3000's first album, Richard Wright's 1945 autobiography was published, and Wright articulated many of the challenges confronting southern black boys seeking to defy standard racial conventions in favor of pursuing more creative and intellectual endeavors. At age twelve, the young Wright was developing an "enthralling sense of wonder and awe"; however, his budding artistic and intellectual interests were constantly thwarted by family members and the larger societal structures of Jim Crow, both of which were disinterested in and frequently hostile to facilitating a viable creative environment for young black boys. ${ }^{17}$ Much had changed between the publication of Wright's Black Boy and OutKast's Southernplayalisticadillacmuzik. However, what remained constant was the fact that black men outliers relied on special opportunities and extraordinarily supportive systems or networks.

The words "systems" or "networks" are noteworthy here given the attentiveness in Afrofuturist discourse to technological lexicon and concepts and also, more important, because those terms signal the multithreaded, complex processes of guidance, influence, assistance, emotional support, inspiration, training, mentoring, failed attempts, constructive feedback, collaboration, funding, and more that make high-level artistic production possible and sustainable. Just as systems are capable of providing tremendous support, they can also enable devastating neglect and worse. Michelle Alexander, among others, makes it painfully evident in her book The New Jim Crow: Mass Incarceration in the Age of Colorblindness that what we have in this country are powerful racially discriminate networks of control designed to systematically restrict the life chances of black men. On OutKast's third album, Aquemini, an imprisoned 
black man presumably named "Nathaniel" performs a freestyle rap where he provides a glimpse of his experiences behind bars. Given the nature of networks of neglect versus networks of support, far too many African American men are more likely, unfortunately, to end up in the criminal justice system like Nathaniel as opposed to becoming the beneficiaries of encouraging creative environments like André 3000.

\section{Notes}

1. There is a rich and prevalent tradition in African American culture associated with lying (or "storying" as Kevin Young labels it), masking, signifying, indirection, passing, sarcasm, code switching, and other practices associated with covert and concealed modes of expression and existence. See Kevin Young's The Grey Album: On the Blackness of Blackness. Minneapolis: Graywolf Press, 2012.

2. Alondra Nelson, "Afrofuturism,": Past-Future Visions." Color Lines (Spring 2000): 34-37.

3. For the purposes of this essay, I have decided to focus primarily on OutKast's first two albums as opposed to their entire body. My concern, for now, is to offer points concerning the group's foundations.

4. Jon Caramanica, "Hip-Hop's Raiders of the Lost Archives." New York Times. June 26, 2005. http://www.nytimes.com/2005/06/26/arts/music/26jon.html, Accessed September 30, 2013.

5. Lewis Porter, John Coltrane: His Life and Music. Ann Arbor: The University of Michigan Press, 1999. 72.

6. Paul F. Berliner, Thinking in Jazz: The Infinite Art of Improvisation. Chicago: The University of Chicago Press, 1994. 102-8.

7. Rob Marriott, Southernplayalisticadillacmuzik, Review. The Source. (July 1994): 83.

8. Alondra Nelson, "Afrofuturism," 35.

9. Quoted in John F. Szwed, Space Is the Place: The Lives and Times of Sun Ra. New York: Da Capo Press, 1998. 173.

10. Kevin Powell, review ATLiens Rolling Stone,. Posted: Oct 31, 1996. http://web.archive. org/web/20071001015629/http://www.rollingstone.com/artists/outkast/albums/album/301210/review/6067352/atliens, Accessed September 30, 2013.

11. Tricia Rose, The Hip Hop Wars: What We Talk about When We Talk about Hip Hop-and Why It Matters. New York: Basic Books, 2008. 141.

12. Prior to coordinating major projects related to Afrofuturism, Alondra Nelson founded the AfroFuturism listserv. She writes, "The focus of the listserv was initially on science fiction metaphors and technocultural production in the African diaspora and expanded from there into a freewheeling discussion of any and all aspects of contemporary black life." Participants on the list, many of whom were musicians or music aficionados, regularly discussed the particular techniques that musical artists used to produce certain sounds. Some of the DJs, for instance, discussed how turntablists created distinct sonic effects by touching records in various ways. Observing such discussions revealed and advanced a heightened awareness concerning distinct technical approaches. See Alondra Nelson, "Introduction: Future Texts," in Afrofuturism: A Special Issue of Social Text. Ed. Alondra Nelson. Vol. 20. No. 2. Durham: Duke University Press, 2002. 15.

13. Malcolm Gladwell, Outliers: The Story of Success. New York: Little, Brown and Company, 2008. 19.

14. There is frequent mention of "conscious" rappers but considerably less discussion of the communities that give rise to those conscious black men. For decades now, cities such as New York; Chicago; Atlanta; Jackson, Mississippi; New Orleans; and Philadelphia have been home to loosely defined communities of black men who might be labeled "conscious," "street scholars," and "deep." An important influence on the politically astute intellectualism of rap has been Malcolm X and the Nation of Islam, often through the teachings of Five Percenters. See, for instance, Felicia Miyakawa, Five Percenter Rap: God Hop's Music, Message, and Black Muslim Mission. Indiana University Press: Bloomington, 2005.

15. Often meeting in Organized Noize cofounder Rico Wade's basement to produce their recordings, the Dungeon Family was comprised of a dozen or so artists, including Cee-Lo Green, Big Gipp, T-Mo, Khujo of Goodie Mob, Big Boi, Mr. DJ, "Sleepy” Brown, Big Rube, and Cool Breeze. 16. André 3000 confirms on his song "A Life in the Day of Benjamin Andre," from The Love Below that he had stopped smoking and drinking at the time of the second album.

17. Richard Wright, Black Boy (American Hunger), A Record of Childhood and Youth. New York: Perennial Classics, 1998. 100-101. 


\section{Works Cited}

Alexander, Michelle. The New Jim Crow: Mass Incarceration in the Age of Colorblindness. New York: New Press, 2010.

Anderson, Elijah, ed. Against the Wall: Poor, Young, Black, and Male. Philadelphia: University of Pennsylvania Press, 2009.

Berliner, Paul F. Thinking in Jazz: The Infinite Art of Improvisation. Chicago: University of Chicago Press, 1994.

Caramanica, Jon. "Hip-Hop's Raiders of the Lost Archives." New York Times. http://www.nytimes.com/2005/06/26/arts/music/26jon.html, Accessed September 30, 2013.

Gladwell, Malcolm. Outliers: The Story of Success. New York: Little, Brown, 2008.

Marriot, Rob. Review. Southernplayalisticadillacmuzik. The Source, July 1994, 83.

Mincy, Ronald B., ed. Black Males Left Behind. New York: Urban Institute Press, 2006.

Miyakawa, Felicia. Five Percenter Rap: God Hop's Music, Message, and Black Muslim Mission. Bloomington: Indiana University Press, 2005.

Nelson, Alondra. "Afrofuturism: Past-Future Visions." Color Lines, Spring 2000, 34-37.

Nelson, Alondra, ed. Afrofuturism: A Special Issue of Social Text. Vol. 20, no.

2. Durham, NC: Duke University Press, 2002.

OutKast. Southernplayalisticadillacmuzik. LaFace, 26010, 1994, compact disc. . ATLiens. LaFace 26029 1996, compact disc. . Aquemini. LaFace 26053 1998, compact disc.

Speakerboxxx/The Love Below. LaFace 50133 2003, compact disc.

Porter, Lewis. John Coltrane: His Life and Music. Ann Arbor: University of Michigan Press, 1999.

Powell, Kevin. Review. ATLiens, Rolling Stone. http:/web.archive.org/ web/20071001015629/http://www.rollingstone.com/artists/outkast/albums/album/301210/review/6067352/atliens, Accessed September 30, 2013.

Rose, Tricia. The Hip Hop Wars: What We Talk about When We Talk about Hip Hop - and Why It Matters. New York: Basic Books, 2008.

Szwed, John F. Space Is the Place: The Lives and Times of Sun Ra. New York: Da Capo Press, 1998.

Wilson, William J. When Work Disappears: The World of the New Urban Poor. New York: Vintage, 1997.

Wright, Richard. Black Boy (American Hunger): A Record of Childhood and Youth. New York: Perennial Classics, 1998.

Young, Kevin. The Grey Album: On the Blackness of Blackness. Minneapolis: Graywolf Press, 2012. 